\title{
A FORMAÇÃO CONTINUADA DE PROFESSORES \\ ALFABETIZADORES E AS CONTRIBUIÇÕES DE UM PROJETO \\ DE LETRAMENTO
}

\author{
Ariane Ranzani \\ Universidade Federal de São Carlos
}

\section{Resumo}

Este artigo visa refletir sobre como um curso a distância de formação continuada de professores alfabetizadores pode contribuir para atividade pedagógica docente por meio de projetos de letramento com crianças de seis anos de um primeiro ano do Ensino Fundamental. O referencial teórico fundamenta-se nos conceitos de atividade e sentido pessoal da Teoria da Atividade, desenvolvida por Leontiev (1978, 2006a, 2006b) a partir da perspectiva sócio-histórica e de projetos de letramento dos Estudos do Letramento (KLEIMAN, 2000, 2001, 2006, 2007, 2008, 2009, 2012; MARTINS, 2007, 2008; OLIVEIRA, 2010; TINOCO, 2008). Desenvolvida sob o paradigma qualitativointerpretativo, tais reflexões evidenciam que o projeto de letramento desencadeia um outro olhar para a atividade pedagógica docente, pois além de poder salientar a importância do professor, da sua mediação, ainda, permite que as crianças entrem em atividade, motivadas socialmente, aprendendo e usando a linguagem escrita por meio de diferentes gêneros discursivos.

Palavras-chave: projetos de letramento, formação continuada de professor, ensino da linguagem escrita. 


\title{
CONTINUING EDUCATION FOR LITERACY TEACHERS AND THE CONTRIBUTIONS OF A LITERACY PROJECT
}

\begin{abstract}
The article intends to reflect on how an e-learning course of continuing education for literacy teachers may contribute to the teacher's pedagogical activity through literacy projects with six-year-old children of the first year of elementary school. The theoretical framework is based on the concepts of activity and personal sense of Activity Theory, developed by Leontiev $(1978,2006 a, 2006 b)$ from the socio-historical perspective and literacy projects of New Literacy Studies (KLEIMAN, 2000, 2001, 2006, 2007, 2008, 2009, 2012; MARTINS, 2007, 2008; OLIVEIRA, 2010; TINOCO, 2008). This study, which is based on the qualitative-interpretative paradigm, shows that literacy projects reveal another aspect of the teacher's pedagogical activity, highlighting the importance of teachers and their mediation as well as allowing children to get into the, socially motivated activity, learning and using the writing language through different discursive genres.
\end{abstract}

Keywords: literacy projects, teacher's continuing education, writing language teaching. 


\section{Introdução}

O presente artigo é fruto de uma parte da dissertação de Mestrado intitulada $A$ formação de professores a distância e o acesso de crianças de seis anos à linguagem escrita através de projetos de letramento $^{1}$ e busca compreender quais contribuições um curso de formação continuada, desenvolvido em um ambiente virtual de aprendizagem, pode fornecer, de maneira que possa proporcionar ao professor reflexões para uma atividade pedagógica docente mais significativa para si e também para as crianças de seis anos de idade ao se desenvolver um projeto de letramento.

Para tanto, serão tomados como dados para análise o projeto de letramento $O$ massacre das lagartas desenvolvido por uma professora participante do ambiente virtual de aprendizagem (AVA) Estudo de Textos no Primeiro Ano - Ensino Fundamental (ETPA) com crianças de um primeiro ano do Ensino Fundamental de uma escola pública estadual de São Carlos, interior do estado de São Paulo. A seleção deste projeto de letramento foi porque, enquanto pesquisadora tive a possibilidade de acompanhá-lo como professora e tutora do AVA e também em sala de aula interagindo com a professora, com as crianças e outras pessoas da escola, obtendo, assim, mais informações por outras fontes, além do AVA, propiciadas pela observação participante realizada durante várias aulas nos meses de agosto a novembro de 2012 .

Esse projeto, $O$ massacre das lagartas, iniciou quando a professora percebeu que as lagartas que apareciam pela escola estavam sendo pisoteadas pela sua turma. Diante dessa constatação, ela começou a buscar informações sobre o inseto com as crianças, desde a observação de lagartas e casulos que apareciam pela escola até

\footnotetext{
${ }^{1}$ RANZANI, A. A formação de professores a distância e o acesso de crianças de seis anos à linguagem escrita através de projetos de letramento. Dissertação (Mestrado in Linguística). São Carlos: Universidade Federal de São Carlos, 2014. Disponível em: http://www.bdtd.ufscar.br/htdocs/tedeSimplificado/tde busca/arquivo.php?codArquivo=7395. Acesso em: 26 set. 2014.
}

Olh@res, Guarulhos, v. 2, n. 2, p. 179-202. Dezembro, 2014. 
pesquisas feitas em casa, na biblioteca da escola e em diversos sites no laboratório de informática. Para a realização da pesquisa, a professora e sua turma também trocaram e-mails com pesquisadores do Centro de Divulgação Científica e Cultural, o CDCC, que é vinculado à USP de São Carlos/SP. Durante todo esse processo, as hipóteses, observações e descobertas da turma foram registradas por meio de diferentes linguagens, no entanto, por ser um projeto de letramento, o foco foi na linguagem escrita. Dessa maneira, foram desenvolvidas atividades de escrita e leitura que envolviam diferentes componentes curriculares e o uso e a aprendizagem de diferentes gêneros discursivos: contos, convite, e-mails, verbetes, bilhetes, legendas, artigos de diversos livros e revistas científicas, entre outros. A escrita de cada texto dos diversos gêneros discursivos sempre estava atrelada a sua função social, assim as crianças redigiram bilhetes para os pais informando sobre as atividades que deveriam fazer em casa, escreveram o convite para chamar as demais turmas da escola para a exposição do projeto, preencheram um calendário para registrar diariamente o que acontecia com um casulo, confeccionaram um livro de curiosidades para registrar descobertas interessantes, cantaram acompanhando a legenda da música Metamorfose da borboleta do programa infantil Cocoricó, entre outras atividades. Toda a pesquisa e os registros feitos no projeto de letramento resultaram em uma exposição, com tudo o que foi produzido pelas crianças, na qual elas apresentaram: a leitura oral de textos narrativos, livros diversos, maquetes, borboletários, fotos e, ainda, deram brindes para os visitantes.

Durante o período em que ocorreu o curso ETPA e o desenvolvimento do projeto de letramento, a professora alfabetizadora teve a possibilidade de compartilhar as atividades, que desenvolvia na sala de um primeiro ano, no AVA, e ainda pode refletir sobre esse processo com outras professoras alfabetizadoras a partir de diferentes textos teóricos disponibilizados para leitura no curso.

Para a análise dos dados coletados, tanto no ambiente virtual de aprendizagem quanto na escola pública estadual por meio da observação participante, foram utilizados os conceitos de atividade e Olh@res, Guarulhos, v. 2, n. 2, p. 179-202. Dezembro, 2014. 
sentido pessoal da Teoria da Atividade (LEONTIEV, 1978, 2006a, $2006 \mathrm{~b}$ ) e de projeto de letramento, a partir dos Estudos do Letramento (KLEIMAN, 2000, 2001, 2006, 2007, 2008, 2009, 2012; MARTINS, 2007, 2008; OLIVEIRA, 2010; TINOCO, 2008), um modelo didático que possibilita o trabalho com a linguagem escrita de uma maneira mais significativa tanto para a criança quanto para o professor. Dessa maneira, selecionamos alguns relatos que detalham as contribuições do curso de formação continuada a distância, com foco nos projetos de letramento, dessa professora alfabetizadora acima citada.

\section{A Teoria da Atividade}

A Teoria da Atividade, desenvolvida por Leontiev (1978, 2006a, 2006b) a partir da perspectiva sócio-histórica, considera que o ser humano é produto do momento histórico e da sociedade cultural de que participa, por isso seu desenvolvimento é resultado do seu processo de aprendizagem. Sendo assim, é pela atividade que o ser humano apropria-se do produto histórico e social da humanidade ao agir sobre a realidade mediado por instrumentos e signos, produzidos culturalmente, transformando-os e transformando a si mesmo nessa relação dialética entre o homem e o meio social e cultural (LIBÂNEO \& FREITAS, 2006).

Nesse sentido, Leontiev (2006a, p. 68) denomina de atividade:

Os processos psicologicamente caracterizados por aquilo a que o processo como um todo, se dirige (seu objeto), coincidindo sempre com o objetivo que estimula o sujeito a executar esta atividade, isto é, o motivo.

Com o objetivo de ilustrar esse conceito, o autor utiliza o exemplo de um estudante que está lendo um livro de História para ser aprovado em um exame, quando é avisado por um colega que tal livro não é necessário para o exame. Diante dessa situação, ele pode interromper a leitura, prosseguir ou desistir com certa resistência. Assim, segundo o autor, nos dois últimos casos foi o conteúdo do livro 
o motivo da leitura, havia uma necessidade de entender, conhecer, compreender melhor o assunto abordado pelo livro. No entanto, no primeiro caso em que o estudante abandona a leitura, ao descobrir que o livro não é necessário ao exame, nota-se que o motivo de tal leitura era a necessidade de aprovação no exame. Portanto, no momento em que a leitura do livro não coincidiu com o que motivava o estudante a ler, ou seja, quando leu o livro não pelo conteúdo, pelo conhecimento, mas pela aprovação no exame, essa leitura não era propriamente uma atividade, mas apenas uma ação. A atividade apenas existe se há um motivo que a impulsiona, articulando a necessidade a um objeto. $\mathrm{O}$ autor explica ainda que motivos são desenvolvidos no ser humano pela sociedade, a partir das condições de vida e da escolarização, assim, eles são considerados históricos e sociais.

Para Leontiev (2006a, p. 70) há os motivos apenas compreensiveis e os motivos realmente eficazes, sendo o primeiro esclarecido com o exemplo de uma criança que faz sua lição apenas para não ser proibida de sair para brincar e o segundo, os motivos realmente eficazes, com o de uma criança que passa a fazer a lição porque entende que esse é um motivo eficaz para, além de brincar, poder aprender e cumprir seu dever da escola. Dessa maneira, os motivos somente tornam-se eficazes se forem compreensíveis, com isso, surgem novos motivos e novos tipos de atividades.

A interação com o meio e com o outro, mediada por instrumentos socialmente construídos, segundo Leontiev (1978), possibilita ao ser humano apropriar-se dos conhecimentos sóciohistoricamente construídos por meio de um processo de reorganização da sua atividade psicológica a partir da interação social e que proporciona transformações no indivíduo, ou seja, o seu desenvolvimento. De tal modo, todas essas relações são estabelecidas através da atividade humana.

A fim de esclarecer outro conceito importante da teoria desenvolvida por Leontiev, ou seja, o sentido pessoal, é retomado o exemplo utilizado ao explicar o conceito de atividade: o de um aluno que lê um livro de História. A significação da leitura será assimilar o Olh@res, Guarulhos, v. 2, n. 2, p. 179-202. Dezembro, 2014. 
conteúdo do livro, no entanto, o sentido pessoal da leitura realizada por esse aluno dependerá do motivo que o estimula a ler. Portanto, para analisar a atividade desse aluno, é preciso descobrir qual é o motivo que gera o sentido pessoal.

Segundo Leontiev, a significação, que se transforma de acordo com as mudanças sociais, históricas e culturais, é:

\begin{abstract}
a generalização da realidade que é cristalizada e fixada num vector sensível, ordinariamente a palavra ou a locução. É a forma ideal, espiritual da cristalização da experiência e da prática sociais da humanidade. A sua esfera das representações de uma sociedade, a sua ciência, a sua língua existem enquanto sistemas de significações correspondentes. A significação pertence, portanto, antes de mais, ao mundo dos fenômenos objectivamente históricos. (LEONTIEV, 1978, p. 94)
\end{abstract}

Assim, enquanto as significações pertencem à consciência social, fazem parte de um sistema elaborado historicamente, o sentido pessoal é produzido na vida do sujeito pela sua atividade. Ao nascer, o ser humano encontra prontas essas significações que estão em constante transformação, no entanto, cabe a ele apropriar-se ou não delas, dependendo do sentido pessoal que tenham para ele. É por isso que o sentido pessoal e o motivo estão intimamente relacionados já que para encontrar o primeiro é preciso descobrir o seu motivo correspondente (LEONTIEV, 1978, p. 96-97).

Dessa maneira, quando o foco é na atividade pedagógica docente, é preciso considerar que se o sentido pessoal dessa atividade não coincidir com o seu significado social, esta será considerada como alienada, segundo o autor, já que o "resultado é que sua própria actividade deixa de ser para o homem o que ela é verdadeiramente." (LEONTIEV, 1978, p. 121).

Além disso, quando se aborda a atividade da criança, esse autor afirma que são as experiências que ela vive que impulsionam o seu desenvolvimento:

$\mathrm{O}$ que determina diretamente o desenvolvimento da psique de uma criança é sua própria vida e o desenvolvimento dos processos reais desta vida - em outras palavras: o desenvolvimento da atividade da criança, quer a atividade aparente, quer a atividade

Olh@res, Guarulhos, v. 2, n. 2, p. 179-202. Dezembro, 2014. 
interna. Mas seu desenvolvimento, por sua vez, depende de suas condições reais de vida. (LEONTIEV, 2006a, p. 63)

Logo, a análise da atividade da criança fornece subsídios ao professor que pode intervir de maneira mais ativa no processo de desenvolvimento infantil. Para que isso ocorra, a significação social da atividade pedagógica do professor, ou seja, proporcionar condições para que o aluno participe de atividades que propiciem a apropriação de conhecimentos sócio-historicamente construídos, precisa coincidir com o sentido pessoal, caso contrário, como já dito, essa ruptura produz uma atividade alienada por deixar de ser para o professor a atividade que realmente é, que possibilita a apropriação de tais conhecimentos.

De acordo com Asbahr (2005, p.114-5), se a significação da atividade pedagógica do professor é a de garantir ao aluno a apropriação de conhecimento científico, a finalidade dessa ação é produzir o desenvolvimento psíquico da criança. Nesse sentido, tornase importante entender qual é a significação da atividade pedagógica docente que é essencial para a compreensão do sentido dessa sua atividade, ou seja, daquilo que o motiva a realizá-la.

Considerando que a apropriação dos conhecimentos científicos é fundamental para o desenvolvimento psicológico humano, a educação deve ampliar os horizontes culturais do aluno. De tal modo, concluem Arce e Martins (2007, p. 53), para as atividades principais se efetivarem é preciso que os conteúdos culturais sejam interiorizados e para isso é preciso a participação de um adulto organizando e conduzindo atividades que atuem no processo psíquico da criança. É por isso que o ensino é necessário ao processo de desenvolvimento infantil.

Dessa forma, as contribuições propiciadas, a partir dos conceitos de atividade e sentido pessoal advindos da Teoria da Atividade, à atividade pedagógica se referem tanto à formação continuada dos professores alfabetizadores quanto à aprendizagem da escrita pelas crianças de seis anos de idade. Destarte, como argumenta Basso (1998, p. 10), o professor bem sucedido consegue integrar a 
significação social e o sentido pessoal do seu trabalho docente concretizando uma atividade pedagógica mais significativa para si e para a criança. Ao considerar os conceitos de atividade e sentido pessoal, é necessário refletir sobre possíveis contribuições para a organização de um ensino em que a produção coletiva das crianças de seis anos de idade, dos professores alfabetizadores do AVA do curso ETPA e dos formadores, possibilite uma educação mais humanizadora, já que para Leontiev (2006b), o processo de humanização ocorre na medida em que a criança age sobre os objetos do seu meio, passa a compreender suas funções para então reproduzir seus usos.

É nesse sentido de uma educação mais humanizadora que também é utilizado o conceito de projetos de letramento como veremos a seguir.

Os Estudos do Letramento, a Pedagogia de Projetos e os Projetos de Letramento

Para prosseguir a discussão sobre os projetos de letramento, primeiro serão abordados os Estudos do Letramento e, em seguida, a Pedagogia de Projetos como forma de contextualização do conceito.

Os Estudos do Letramento são embasados na concepção de que a leitura e a escrita devem estar direcionadas às práticas sociais e culturais às quais pertencem e não focadas no indivíduo. Dessa forma, a corrente teórica conhecida por New Literacy Studies (KLEIMAN, 2008) ou os Estudos do Letramento, como é conhecida aqui no Brasil, evidencia a relevância do trabalho com a escrita que envolve as práticas sociais.

Para a autora, o letramento é "um conjunto de práticas sociais que usam a escrita, como sistema simbólico e como tecnologia, em contextos específicos, para objetivos específicos." (KLEIMAN, 2008, p. 18-19) assim é essencial que a escola torne-se a agência de 
letramento mais importante na vida dessa pessoa (KLEIMAN, 2008, p. 20).

Disso decorre uma visão de educação que compreende os conhecimentos dos alunos e entende o processo de ensino e aprendizagem como uma construção de saberes na qual o aluno, assim como o professor, precisa ser um sujeito ativo. Nesse sentido, aponta Tinoco, “[...] não há 'UM' letramento para o qual possamos fazer uma proposta globalizadora de ensino-aprendizagem, mas diferentes letramentos." (2008, p. 115).

Considerando a importância da atividade pedagógica docente e da atividade que envolve a apropriação da linguagem escrita por crianças do primeiro ano do Ensino Fundamental, será resgatada um pouco da trajetória da Pedagogia de Projetos para uma melhor compreensão dos projetos de letramentos nesse contexto.

Foi com o filósofo e pedagogo americano John Dewey que a Pedagogia de Projetos surgiu, no início do século $\mathrm{XX}$, como uma forma de evitar um ensino fragmentado, autoritário e repetitivo, propondo assim, uma metodologia em que o conhecimento deve ser dirigido para a experiência, e a educação deve ser uma prática coletiva. Em 1919, o pedagogo Willian Kilpatrick foi quem sistematizou em sala de aula o método de projetos. Posteriormente, com a expansão da escola pública, gratuita e laica e o Manifesto dos Pioneiros da Escola Nova (1932), o método de uso de projetos na sala de aula ganhou força no Brasil com Anísio Teixeira, Lourenço Filho, Fernando de Azevedo, Paschoal Lemme, entre outros, que visavam uma "aprendizagem significativa, aquela que oferece parâmetros para a ação e possível transformação do mundo social" (TINOCO, 2008, p. 169). No fim dos anos 90, simultaneamente ao lançamento dos Parâmetros Curriculares Nacionais que buscavam garantir a todos o direito a um conhecimento necessário para o exercício da cidadania (BRASIL, 1997), ganharam destaque em nosso país os estudos de Fernando Hernández e Montserrat Ventura sobre os projetos de trabalho e de Josette Jolibert sobre a pedagogia de projetos em sala aula.

Olh@res, Guarulhos, v. 2, n. 2, p. 179-202. Dezembro, 2014. 
Recentemente, foram lançados os cadernos de formação do Pacto Nacional pela Alfabetização na Idade Certa ${ }^{2}$ (PNAIC) que diante da relevância de entender quais são as necessidades e interesses das crianças de seis anos, ressalta, em alguns de seus cadernos, a coerência que existe entre o desenvolvimento dos projetos didáticos e as especificidades das crianças dessa faixa etária, além da promoção da alfabetização e do letramento. Tais cadernos também citam estudos sobre projetos de vários autores e destacam o trabalho com diferentes gêneros discursivos em diversas áreas de conhecimento.

Acompanhado por diferentes adjetivações, o termo projeto já faz parte do discurso escolar há anos, dependendo da área de conhecimento que lhe dá embasamento teórico, do objetivo, da esfera a partir da qual se desenvolve e do contexto em que é utilizado, segundo Tinoco (2008). A autora ainda afirma que esses projetos buscam uma prática recontextualizada e requerem: reflexão dos envolvidos, diferentes espaços e momentos, motivações e busca de metas pré-definidas. Por isso, o trabalho com projetos na escola precisa ser uma escolha consciente de cada professor e não algo imposto.

Diante disso, o projeto de letramento, mais especificamente, pode tornar-se um interessante aliado para $o$ desenvolvimento de atividades significativas de escrita, pois segundo Tinoco (2008, p. 175-176), ele viabiliza, ainda, a reflexão na ação e sobre a ação. Assim, partindo do pressuposto que o trabalho com a escrita e a leitura no primeiro ano do Ensino Fundamental deve estar em consonância com o universo infantil (BAPTISTA, 2010) e que o projeto de letramento é um modelo didático que pode ressignificar o ensino da escrita (TINOCO, 2008), há a possibilidade de discutir a relevância do seu desenvolvimento com crianças de seis anos de idade no primeiro ano.

Segundo Kleiman (2000, p. 238):

2 Acordo formal entre o Governo Federal, os estados, municípios e entidades que aderiram ao compromisso de alfabetizar as crianças até o final do ciclo de alfabetização, ou seja, aos 8 anos de idade. Olh@res, Guarulhos, v. 2, n. 2, p. 179-202. Dezembro, 2014. 
O projeto de letramento é uma prática social em que a escrita é utilizada para atingir algum outro fim, que vai além da mera aprendizagem da escrita (aprendizagem dos aspectos formais apenas), transformando objetivos circulares como 'escrever para aprender a escrever' e 'ler para aprender a ler' em ler e escrever para compreender e aprender aquilo que for relevante para o desenvolvimento e a realização do projeto.

Ele pode tornar a escrita mais significativa, pois propicia uma grande variedade de situações de leitura e registro de experiências através da escrita, além de levar o professor a assumir uma posição de professor/ pesquisador, conforme Martins (2008). Assim, independentemente do tema ou do objetivo, ele tem "potencial para mobilizar conhecimentos, experiências, capacidades, estratégias, recursos, materiais e tecnologias de uso de língua escrita de diversas instituições cujas práticas letradas proporcionam os modelos de uso de textos aos alunos." (KLEIMAN, 2007, p. 16). Ademais, esse tipo de projeto possibilita ao professor "pensar a teoria com base na prática" (KLEIMAN, 2001, p.8).

Considerando que muitas atividades humanas estão relacionadas à apropriação da língua e que tanto essas atividades quanto os gêneros discursivos ${ }^{3}$ são bastante diversificados, o acesso e o domínio da linguagem escrita, por crianças de seis anos, por meio de diversos gêneros discursivos propiciam o seu desenvolvimento cultural. A linguagem, seja ela oral ou escrita, é um instrumento mediador simbólico que possibilita a transformação cognitiva e afetiva da criança. Dessa maneira, o professor pode planejar atividades, no sentido dado por Leontiev (2006a), que envolvam o discurso letrado de maneira que a criança tenha interesse em participar, interaja com outras pessoas e aprenda ao trabalhar com os gêneros. Sobre isso afirma Oliveira:

O ensinar e o aprender nos projetos de letramento se efetivam por meio do trabalho com os gêneros, entendidos como instrumentos mediadores da ação humana no mundo - em termos didáticos - o eixo organizador das atividades com a linguagem. Nessa perspectiva, os projetos 'preveem uma concepção

\footnotetext{
${ }^{3}$ Segundo Bakhtin (2003), os gêneros discursivos correspondem a todo e qualquer enunciado, relativamente estável, que tenha uma função sociocomunicativa dentro da sociedade, seja ele oral ou escrito; são transmitidos sócio-historicamente pelos falantes que, ao mesmo tempo, contribuem para a sua preservação e mudança; e são caracterizados por três elementos completamente relacionados entre si: a estrutura composicional, o tema e o estilo.

Olh@res, Guarulhos, v. 2, n. 2, p. 179-202. Dezembro, 2014.
} 
transdisciplinar de conhecimento, uma visão aberta ou integrada de currículo, uma ruptura em relação ao tempo e espaço lineares e a processos hierárquicos, uma concepção de aprender diferenciada que leva em conta 'formas de aprendizagem situadas' mobilização social, intersubjetividade, dialogismo e reflexividade' (OLIVEIRA, 2010, p. 340).

Após discorrer sobre a importância da Teoria da Atividade e dos Estudos do Letramento, serão abordadas, a seguir, algumas contribuições do curso ETPA no desenvolvimento da atividade pedagógica de uma docente que trabalhou com um projeto de letramento com crianças de um primeiro ano do Ensino Fundamental.

As contribuições do curso de formação continuada para o desenvolvimento da atividade pedagógica docente

O curso ETPA ocorreu em um AVA na plataforma Moodle da Universidade Federal de São Carlos, UFSCar, como parte de uma de suas ACIEPEs, (Atividade Curricular de Integração Ensino, Pesquisa e Extensão) que, por sua vez, visam fortalecer as três atividades essenciais da universidade: o Ensino, a Pesquisa e a Extensão. Ele foi destinado a professores alfabetizadores com o objetivo de analisar o trabalho com textos no primeiro ano do Ensino Fundamental; no entanto, outros participantes, entre eles estudantes, diretores e coordenadores pedagógicos também puderam participar. $\mathrm{O}$ curso foi dividido em duas etapas: a primeira de oito semanas, em que os professores alfabetizadores refletiram sobre textos teóricos e começaram a planejar e aplicar o projeto de letramento na sala de aula, e a segunda, com duração de cinco semanas em que os projetos em andamento em sala de aula foram compartilhados no AVA para que os professores pudessem discutir, dialogar, interagir.

Logo na primeira semana do curso, a professora do primeiro ano, que trabalhou com o projeto de letramento $O$ massacre das lagartas, fez registros sobre o que pode causar a falta de 
motivação dos professores em geral e isso tende a repercutir na consciência docente:

Apesar das dificuldades enfrentadas no trabalho (barulho excessivo por conta de uma quadra de frente para a sala, 31 alunos, calor, falta de espaço, pais que querem saber onde está o lápis do filho ou quem brigou com o filho, a correria do dia-a-dia, falta de material principalmente de impressão, cobrança de sondagens individuais mês a mês, avaliações e outros) procuro sempre oferecer às crianças o melhor que consigo relacionando a teoria à prática.

Assim, acredito que o conhecimento é o único caminho para enfrentarmos tantos obstáculos. (Fórum, $1^{\mathrm{a}}$ semana da $1^{\mathrm{a}}$ etapa do ETPA)

Segundo Asbahr (2005, p. 11), a alienação da atividade pedagógica apenas pode ser compreendida ao se analisar as condições objetivas (falta de recursos, jornada de trabalho, baixos salários) e as subjetivas (formação teórica e acadêmica) do trabalho docente. Assim, notamos que apesar das condições objetivas da atividade pedagógica da professora apontarem para uma alienação dessa atividade, a sua formação acadêmica e o que ela utiliza como fundamentação teórica para suas aulas apontam para a necessidade de reflexão, de diminuir a distância entre o conhecimento acadêmico adquirido nos cursos de licenciatura ou de formação continuada e a realidade da escola pública. Dessa forma, o projeto de letramento realizado na sala de aula e discutido no AVA pode ser considerado como algo que possibilitou a reflexão e a reorganização de atividades em busca da não alienação docente.

Para Oliveira (2010, p. 340):

\begin{abstract}
Considerados como uma 'prática de letramento', os projetos se inserem num tipo de cultura escolar alternativa em que a produção do conhecimento está orientada pela abordagem de 'resolução de problemas', comumente adotada em outras áreas disciplinares. Tendo como ponto de partida a prática social, esses projetos visam atender a necessidades sociais e demandas comunicativas específicas de um determinado grupo, a partir de ações coletivas.
\end{abstract}

Sendo assim, um dos pontos a ser destacado no projeto foi seu elemento propulsor: um problema da escola e que, rapidamente, foi identificado pela professora, conforme relato feito em seu diário reflexivo no AVA:

Sabe, logo que entrei na minha escola um monte de lagarta aparecia pela janela, tentei pegar a chave do portão para chegar até o jardim e observar com

Olh@res, Guarulhos, v. 2, n. 2, p. 179-202. Dezembro, 2014. 
elas ${ }^{4}$, mas é lógico que os "entendidos" de criança não deixaram, disseram que não sabiam onde estava a chave. As lagartas começaram a ser pisoteadas, minhas crianças observavam pelas janelas as folhas que elas se alimentavam, nunca fomos ao jardim nem para pegar uma folhinha...nosso projeto foi morrendo... (Diário, $2^{\mathrm{a}}$ semana da $1^{\mathrm{a}}$ etapa do ETPA)

Apesar das dificuldades iniciais, de algumas condições objetivas serem desfavoráveis, as leituras e discussões no AVA ETPA influenciaram na decisão tomada pela professora fazendo com que ela assumisse "o papel de professor/ pesquisador, atento às atividades de seus alunos, sejam orais ou gráficas, de forma a poder interferir e escolher a metodologia adequada para cada caso, ou para cada período de tempo.”, conforme aponta Martins (2008, p.40). Sobre isso diz a professora do primeiro ano:

Olá pessoal, ao ler o texto da autora Angela Kleiman sobre Projetos de Letramento ${ }^{5}$, posso dizer que, além de adentrar no mundo dos projetos descritos senti uma vontade enorme de começar algo que realmente desperte o interesse das crianças. Na minha turma, estou com casulos em cortinas, forros, armários sendo impossível ignorá-los. Porém ao ler que coisas tão simples, como a história da galinha ruiva, pode ser transformar em algo tão mágico para as crianças, posso dizer que estou totalmente confusa. (Fórum, $5^{\mathrm{a}}$ semana da $1^{\mathrm{a}}$ etapa do ETPA)

No entanto, neste mesmo fórum ela continua:

Ao mesmo tempo, acabamos de receber o material do Ler e Escrever e qual é o projeto para já desenvolvermos com nossa turma??? Brincadeiras.

Assim, não podemos deixar de discutir neste fórum que somos "seguidoras do Ler e Escrever" e que nesse material os projetos já estão prontos. Temos portanto, que ler este material e realizar as atividades sem perceber se é ou não o mais necessário nesse momento. [...] Outra coisa, os mesmos projetos serão repetidos neste ano!!! Será que são tão importantes e mais será que nossas crianças se interessam por eles? Será que alguém releu e ouviu os professores ou só copiaram o material do ano passado? Pensei que estava demorando para chegar nas escolas porque seria melhorado, que nada...

Se as condições objetivas relatadas no fórum da primeira semana "[...] barulho excessivo [...] calor, falta de espaço,

\footnotetext{
${ }^{4}$ As crianças da sua turma.

${ }^{5}$ Referência ao artigo Projetos de Letramento na Educação Infantil (KLEIMAN, 2009). Olh@res, Guarulhos, v. 2, n. 2, p. 179-202. Dezembro, 2014.
} 
[...] falta de material" apontavam para a alienação da sua prática pedagógica assim como o material didático recebido pela escola que trouxe os mesmos projetos já prontos, as condições subjetivas ou as reflexões feitas no fórum demonstraram exatamente o caminho oposto “[...] não podemos deixar de discutir neste fórum [...] Será que são tão importantes e mais será que nossas crianças se interessam por eles?" (grifos meus). Além disso, nota-se que a leitura de um dos textos discutidos durante o curso é que propiciou tal reflexão, ou seja, questionar e compreender as reais necessidades dos alunos (o desenvolvimento de um projeto sobre as lagartas que estavam sendo pisoteadas pelas crianças), refletir sobre o próprio fazer pedagógico (não seguir o material didático naquele momento) na busca de garantir a apropriação de conhecimentos historicamente acumulados por meio da reorganização da atividade pedagógica com projetos de letramento. A afirmação dela "[...] estou totalmente confusa" evidencia o processo de reflexão e de mudanças suscitado pelo curso ETPA.

A indagação da professora sobre o projeto relacionado a brincadeiras proposto pelo material didático: "Será que são tão importantes e mais será que nossas crianças se interessam por eles?" vem reforçar o que Tinoco (2008, p. 175) afirma, ou seja, que o trabalho com projetos na escola deve ser "uma escolha refletida e consciente de cada professor, em particular, e dos componentes da comunidade de aprendizagem, em geral.”, assim não pode ser uma imposição, já que requer reflexão a partir de diversas motivações na busca de metas.

Nesse sentido, a interação da professora no curso de formação também foi fundamental, pois dessa forma ela pode compartilhar saberes que assim são resumidos por Cardoso et al. (2012, p. 4) fundamentados nos estudos de Tardif (2002):

[...] os saberes docentes podem ser provenientes do conhecimento a respeito das ciências da educação e de métodos e técnicas pedagógicas (saberes da formação profissional), do domínio do conhecimento específico a ser ensinado (saberes disciplinares), da apropriação de uma forma 'escolar' de tratar os conhecimentos que serão objeto de ensino (saberes curriculares) ou da própria vivência diária da tarefa de ensinar (saberes experienciais), ao mesmo tempo reconhece que existe um saber específico que é o resultado da

Olh@res, Guarulhos, v. 2, n. 2, p. 179-202. Dezembro, 2014. 
junção de todos esses outros e que se fundamenta e se legitima no fazer cotidiano da profissão.

Esse saber docente é algo plural (TARDIF, 2002) e depende sempre da interação seja durante a sua formação, inicial ou continuada, ou, ainda, durante a trajetória profissional do professor. Esse saber ocorre por meio da interação no AVA com outros alfabetizadores, com os formadores, com as crianças, com os projetos de letramento, enfim, com o meio social e cultural propiciando a não alienação do trabalho da professora.

É válido destacar que conhecer as hipóteses das crianças sobre o assunto, aquilo que elas pensavam a respeito das lagartas e borboletas no início do projeto, auxiliou no (re)planejamento da professora, de forma que ela pode reestruturar a utilização do tempo, do espaço, do currículo, e sua função passou a ser de mediadora entre as crianças e o conhecimento, garantindo que estas se apropriassem de conhecimentos mais elaborados por meio da aprendizagem e do uso de diferentes gêneros discursivos como: o $e$ mail (recebido e enviado para pesquisadores do Centro de Divulgação Científica e Cultural, CDCC, da USP de São Carlos com o objetivo de sanar dúvidas e obter mais informações); o convite (sobre a exposição do projetos e que foi entregue aos professores e crianças das outras turmas da escola); o bilhete (enviado aos pais para explicar sobre o projeto e solicitar auxílio para a confecção de uma maquete); a narrativa (na reescrita da história Romeu e Julieta de Ruth Rocha e de diversas leituras diárias realizadas no início do dia como leitura deleite); o texto instrucional (na elaboração de um manual sobre como montar e cuidar de um borboletário); entre outros.

A atividade pedagógica dessa professora foi organizada por meio da mediação quando planejava, selecionava e organizava as atividades com a linguagem escrita envolvendo diferentes gêneros discursivos, como pode ser observado no relato sobre a sua interação com a professora da outra turma de primeiro ano e com a pesquisadora/ formadora do ETPA: 
Conversamos com a Ariane $^{6}$ e pedimos a ajuda dela para organizar algumas atividades.

Para a primeira semana decidimos organizar todo o conhecimento das crianças, agora ampliado com a pesquisa em conjunto com o Mão na Massa, para atividades de letramento.

Com isso, organizamos escritas de textos em grupos:

1) Reescrita de história: A primavera da lagarta (Ruth Rocha);

2) Manual: Borboletário;

3) Dicionário Ilustrado;

4) Você sabia que...

5) Metamorfose (Fórum $O$ massacre das lagartas, $2^{\mathrm{a}}$ semana da $2^{\mathrm{a}}$ etapa do ETPA).

A interação das crianças em duplas, trios ou grupos mediada pela professora (que organizava os grupos e fazia as intervenções necessárias) ou por diferentes instrumentos (entre eles, revistas, computador, livros) possibilitou que as crianças realizassem atividades que impulsionassem o seu conhecimento. A utilização tanto da língua oral quanto da escrita possibilitou a interação das crianças entre si, o uso de diferentes gêneros discursivos escritos, inclusive aqueles usados nos livros que foram escritos por elas para registro e divulgação da pesquisa e das descobertas feitas, propiciando assim, o acesso ao conhecimento histórico e social.

Nesse contexto, é possível observar que a professora tornou-se uma agente de letramento (Kleiman 2006), que complementa a noção vigotskiana de professor mediador e, segundo, Valsechi (2009, p. 50):

[...] faz emergir os conhecimentos de seus alunos sobre a escrita, leva-os a buscar nas experiências e práticas vivenciadas com a família e/ou comunidade os sentidos que podem atribuir à linguagem escrita.

A professora se assumiu como agente de letramento por meio do projeto de letramento e, esse, por sua vez, tornou-se, além de um modelo didático que permitiu a reflexão no curso de formação continuada e na sala de aula, uma atividade no sentido de possibilitar muitas ações. Esse projeto promoveu a superação de uma possível alienação da atividade pedagógica docente e propiciou reflexões como aquelas que envolvem a decisão sobre qual gênero discursivo deve ser

\footnotetext{
${ }^{6}$ Exceto o nome da pesquisadora, os demais nomes de professores citados na dissertação são fictícios.

Olh@res, Guarulhos, v. 2, n. 2, p. 179-202. Dezembro, 2014.
} 
trabalhado em uma sala de aula de primeiro ano na qual espera-se que as crianças aprendam a linguagem escrita e o seu uso social:

Estou gostando muito de falar sobre gêneros textuais e de poder entender os grupos que cada um faz parte. Sinceramente, é um assunto mal abordado na minha prática, fala-se muito em letramento, mas nunca foquei qual é o gênero mais importante para ser trabalhado com a minha turma. Afinal com o Ler e Escrever os projetos já vêm prontos e temos que ler e realizar sem perceber se é ou não o mais necessário naquele momento. Sabe, uma coisa é trabalhar com a diversidade textual porque temos que trabalhar, outra coisa é entender a necessidade desse trabalho. (Diário, $4^{\mathrm{a}}$ semana da $1^{\mathrm{a}}$ etapa do ETPA - grifo meu)

O trecho citado evidencia a importância da professora compreender a significação social da sua atividade pedagógica com a escrita, ou seja, de propiciar condições para que as crianças do primeiro ano engajem-se em atividades de aprendizagem que envolvam diferentes gêneros discursivos para que "se constituam em produtoras de textos" (MARTINS, 2007, p. 156). Sendo assim, a professora foi a responsável por organizar situações que propiciaram a aprendizagem considerando o que devia ser ensinado e como isso podia ser feito, pois ela foi a mediadora entre essas crianças e o conhecimento, uma agente de letramento.

Segundo Asbahr (2005, p. 10), é fundamental compreender a significação social da atividade pedagógica docente para investigar qual o sentido pessoal dessa atividade, ou melhor, aquilo que o motiva a realizá-la. No projeto de letramento $O$ massacre das lagartas a maneira como as atividades foram organizadas fez com que ele possibilitasse a reflexão da professora, tanto no curso quanto na sala de aula, pois ela almejava que as crianças da sua turma adquirissem os conhecimentos historicamente acumulados tornandose produtoras de textos. Por mais que houvesse projetos prontos no material didático adotado, a reflexão da professora possibilitou a superação de uma prática pedagógica alienada pelo fato de associar a significação social, ou seja, a oferta de atividades com diferentes gêneros discursivos para que as crianças produzam textos, com o sentido pessoal da atividade pedagógica docente, propiciando o acesso Olh@res, Guarulhos, v. 2, n. 2, p. 179-202. Dezembro, 2014. 
de seus alunos aos conhecimentos já existentes socialmente (DUARTE, 2004, p. 56), como os diversos gêneros discursivos trabalhados na sala de aula e que favoreceram o acesso à escrita.

Assim, conforme afirma Asbahr (2005, p. 12), os motivos individuais passam a ser coletivos, tanto para a professora quanto para as crianças que se articulam para alcançar objetivos definidos por meio de ações que passam a ser planejadas, pois isso permite o crescimento pessoal e profissional da professora, além do desenvolvimento psíquico das crianças.

Desse modo, podemos assegurar que o professor para quem o projeto de letramento é significativo ${ }^{7}$, ou seja, para quem a significação social da atividade pedagógica focada no uso e aprendizagem da linguagem escrita coincide com o sentido pessoal, também consegue mobilizar o sentido pessoal dos seus alunos, como ela expressa no trecho a seguir, que elucida o envolvimento tanto da professora quanto da sua turma de primeiro ano:

Sinceramente, as lagartas dominaram e toda e qualquer dúvida que surge as crianças já querem entrar em contato por e-mail com o pessoal do CDCC...tá bom demaisss.... (Fórum - $8^{\mathrm{a}}$ semana da $1^{\mathrm{a}}$ etapa do ETPA)

\section{Considerações finais}

Podemos afirmar que o projeto de letramento foi uma ponte entre a formação continuada de professores alfabetizadores por meio da educação a distância e a atividade pedagógica docente com projetos de letramento. Assim, entre as suas contribuições temos reflexões sobre: a relevância dessa formação continuada como uma maneira de se evitar a alienação docente; a possibilidade de compartilhamento de experiências, angústias, desejos, questionamentos; e, também, o como (incluindo teoria e prática) e o

\footnotetext{
${ }^{7}$ Apesar das reflexões aqui tecidas evidenciarem que a prática pedagógica docente pode tornar-se mais significativa com o desenvolvimento de projetos de letramento, desritualizando a escrita (MARTINS, 2008) e tornando-se uma atividade também para a criança, é preciso frisar que além do projeto de letramento, a professora utiliza outros materiais na sala de aula que não estavam diretamente relacionados ao projeto de letramento $O$ massacre das lagartas.
}

Olh@res, Guarulhos, v. 2, n. 2, p. 179-202. Dezembro, 2014. 
para quê desenvolver atividades pedagógicas relacionadas à linguagem escrita com crianças de seis anos do primeiro ano do Ensino Fundamental de forma que essas atividades façam sentido para todos os envolvidos nesse processo.

O estudo possibilitou, ainda, a compreensão de que quando a formação continuada de professores associa a reflexão da teoria com base na prática, a atividade pedagógica docente passa a ter um sentido pessoal para eles, já que a teoria discutida no AVA estava atrelada à prática da sala de aula, ou seja, havia uma motivação social.

$\mathrm{O}$ projeto de letramento desencadeou um outro olhar para a atividade pedagógica da docente e para as atividades com a linguagem escrita, pois além de poder salientar a importância da professora, dos seus saberes (TARDIF, 2002), da sua mediação na organização das atividades com a linguagem escrita, ele permitiu que as crianças entrassem em atividade, motivadas socialmente, e aprendessem e usassem as linguagens escrita e oral por meio de diferentes gêneros discursivos. É por isso que o projeto de letramento não pode ser algo imposto, é preciso que a escola e os professores conheçam suas potencialidades como uma "organização didática centrada nas práticas sociais de uso da língua escrita" (KLEIMAN, 2012, p. 23) que possibilita uma aprendizagem mais significativa. 
ARCE, A., MARTINS, L. M. (Org.) A Educação Infantil e o Ensino Fundamental de Nove Anos. In: Quem tem medo de ensinar na Educação Infantil? Em defesa do ato de ensinar. Campinas, SP: Editora Alínea, 2007. p. 37-62.

ASBAHR, F. da S. F. A pesquisa sobre a atividade pedagógica: contribuições da teoria da atividade. Revista Brasileira de Educação. Rio de Janeiro, n.29, p.108-118, mai./jun./jul., 2005. Disponível em: <http://www.scielo.br/pdf/rbedu/n29/n29a09.pdf>. Acesso em: 20 fev. 2013.

BAKHTIN, M. Estética da criação verbal. São Paulo: Ática, 2003.

BAPTISTA, M.C. A linguagem escrita e o direito à educação na primeira infância. Centro de Alfabetização Leitura e Escrita - CEALE. Faculdade de Educação da Universidade Federal de Minas Gerais - UFMG, 2010. Disponível em: $<$ http://buscapdf.com.br/procurar/?t=linguagem + escrita\&ws $=\mathrm{gv}>$. Acesso em: 23 set. 2012.

BASSO, I. S. Significado e sentido do trabalho docente. Cad. CEDES. Campinas, v. 19, n. 44, abr. 1998. Disponível em: <http://www.scielo.br/scielo.php? script $=$ sci_arttext\&pid $=\mathrm{S} 0101-32621998000100003 \& \operatorname{lng}=\mathrm{en} \& \mathrm{nrm}=\mathrm{iso}>$. Acesso em: 27 abr. 2012 .

BRASIL. MEC/SEF. Parâmetros Curriculares Nacionais - Ensino fundamental. Brasília/DF: $\quad$ MEC/SEF, $1997 . \quad$ Disponível em: $<$ http://portal.mec.gov.br/seb/arquivos/pdf/ livro01.pdf>. Acesso em: 09 set. 2012.

CARDOSO, A. A.; et al. Os saberes profissionais dos professores na perspectiva de Tardif e Gauhier: contribuições para o campo de pesquisa sobre os saberes docentes no Brasil. In: IX ANPED Sul - Seminário de Pesquisa em Educação da região Sul. Caxias do Sul/ RS, 2013. Disponível em: $<$ http://www.ucs.br/etc/conferencias/index.php/anpedsul/9anpedsul/paper/viewFile/668/ 556>. Acesso em: 29 dez. 2013.

DUARTE, N. Formação do indivíduo, consciência e alienação: o ser humano na psicologia de A. N. Leontiev. Cadernos CEDES. Campinas, vol.24, n.62, p. 44-63, abr. 2004. Disponível em: <http://www.scielo.br/pdf/ccedes/v24n62/20091.pdf > Acesso em: 20 fev. 2013.

KLEIMAN, A. B. O processo de aculturação pela escrita: ensino da forma ou aprendizagem da função? In: SIGNORINI, Inês. O ensino e a formação do professor: alfabetização de jovens e adultos. Porto Alegre: ARTMED, 2000. p. 223 243. 
A formação do professor: perspectivas da linguística aplicada. Campinas, SP: Mercado de Letras, 2001.

Professores e agentes de letramento: identidade e posicionamento social. In: Filologia e Linguística Portuguesa. v. 8, p. 409-424, 2006. Disponível em: $<$ http://www.revistas.usp.br/flp/article/view/59763>. Acesso em: 29 dez. 2013.

. Letramento e suas implicações para o ensino da língua materna. In:

Signo. Santa Cruz do Sul, v.32 n. 53, dez. 2007. Disponível em: $<$ http://online.unisc.br/seer/index.php/signo/article/viewFile/242/196>. Acesso em: 10 jan. 2012.

. Os significados do letramento: uma nova perspectiva sobre a prática social da escrita. Campinas, SP: Mercado de Letras, 2008.

Projetos de Letramento na Educação Infantil. In: Revista Caminhos Em Linguística Aplicada, UNITAU. Volume 1, Número 1, 2009. Disponível em: $<$ http://periodicos.unitau.br/ojs-2.2/index.php/caminhoslinguistica/ article/viewFile/898/ 716>. Acesso em: 10 jan. 2012.

EJA e o ensino da língua materna: relevância dos projetos de letramento. In: Revista EJA em debate. Florianópolis, v. 1, n. 1, nov./2012. Disponível em: <http://incubadora.periodicos.ifsc.edu.br/index.php/EJA\#.UtPh6Z5dXud $>$. Acesso em: 29 dez. 2013.

LEONTIEV, A. N. O desenvolvimento do psiquismo. Lisboa: Livros Horizonte, 1978.

Uma Contribuição à Teoria do Desenvolvimento da Psique Infantil. In: VIGOTSKII, L. S.; LURIA A. R.; LEONTIEV, A. N. Linguagem, desenvolvimento e aprendizagem. São Paulo: Ícone, 2006a. p. 59-83.

Os Princípios Psicológicos da Brincadeira Pré Escolar. In: VIGOTSKII, L. S.; LURIA A. R.; LEONTIEV, A. N. Linguagem, desenvolvimento e aprendizagem. São Paulo: Ícone, 2006b. p. 119-142.

LIBÂNEO, J. C., FREITAS, R. A. M. da M. Vygotsky, Leontiev, Davydov - Três Aportes Teóricos para a Teoria Histórico-Cultural e suas Contribuições para a Didática. IV Congresso Brasileiro de História da Educação - a educação e seus Sujeitos na História. 2006. Disponível em: <http://www.sbhe.org.br/novo/congressos/cbhe4/ individuaiscoautorais/eixo03/Jose $\% 20$ Carlos $\% 20$ Libaneo $\% 20 \mathrm{e} \% 20$ Raquel $\% 20 \mathrm{~A} . \% 20$ M.\%20da\%20M.\%20Freitas\%20-\%20Texto.pdf> Acesso em: 13 de mai. 2013.

MARTINS, M. S. C. A Linguagem Infantil: Oralidade, escrita e gêneros do discurso. In: ARCE, A., MARTINS, L. M. (Org.) Quem tem medo de ensinar na Educação Infantil? Em defesa do ato de ensinar. Campinas, SP: Editora Alínea, 2007. p. 147162.

Mercado $\quad \begin{array}{llr}\text { de } & \text { Letras, }\end{array}$

Olh@res, Guarulhos, v. 2, n. 2, p. 179-202. Dezembro, 2014. 
OLIVEIRA, M. S. Gêneros Textuais e Letramento. In: Revista Brasileira de Linguística Aplicada. Belo Horizonte, v. 10, n. 2, p. 325-345, 2010. Disponível em: $<$ http://wac.colostate.edu/siget/rbla/socorro.pdf $>$ Acesso em: 17 abr. 2012.

TARDIF, M. Saberes docentes e formação profissional. $4^{\text {a }}$ Ed. Rio de Janeiro: Vozes, 2002.

TINOCO, G. M. A. M. Projetos de letramento: ação e formação de professores de língua materna. Tese (Doutorado in Linguística Aplicada). Instituto de Estudos da Linguagem, Unicamp, Campinas, 2008.

VALSECHI, M. C. Desenredando os fios da Teia: análise de um curso de formação continuada no contexto do Programa Teia do Saber. Dissertação (Mestrado in Linguística Aplicada). Instituto de Estudos da Linguagem, Unicamp, Campinas, 2009. 